\title{
Atraumatic bilateral humeral head fracture secondary to single seizure
}

\author{
Amal A. Alduhoori, ${ }^{1}$ Radhakrishnan Renganathan, ${ }^{2}$ Ali Reza Dehdashtian, ${ }^{3}$ \\ Khurram A Siddiqui ${ }^{4}$
}

'Department of Medicine, Al Ain Hospital, Al Ain, United Arab Emirates

${ }^{2}$ Department of Neurology, Al Ain Hospital, Al Ain, United Arab Emirates

${ }^{3}$ Department of Radiology, Al Ain Hospital, Al Ain, United Arab Emirates

${ }^{4}$ Department of Neurology, Al Ain Hospital, Al Ain, United Arab Emirates

\section{Correspondence to} Dr Khurram A Siddiqui, neurology.khurram@yahoo. co.uk

Accepted 25 October 2017

\section{DESCRIPTION}

Case 1: A 51-year-old man presented with a single unprovoked generalised tonic clonic seizure (GTCSz), lasting for $4 \mathrm{~min}$, he developed postseizure bilateral shoulder pain and was unable to move his arms as they were painful; there was a history of seizure 7 years ago, he was not on any antiepileptic drugs (AEDs). His sX-ray shoulder showed bilateral comminuted humeral head fracture, which was confirmed by CT of shoulders, see figure 1.He was started on AEDs from a seizure perspective. His neuroimaging, which included an MRI brain (epilepsy protocol) and electroencephalogram (EEG), were normal, see figure 1. From a shoulder management perspective, he was transferred to an orthopaedic surgeon which resulted in corrective surgery.

Case 2: A 65-year-old man presented with first seizure of his lifetime, GTCSz, lasting for $3 \mathrm{~min}$, developed postseizure bilateral shoulder pain. His shoulder X-ray showed bilateral humeral head fracture, confirmed by CT of shoulders, see figure 2. His EEG and MRI brain were negative. From a shoulder perspective, he was transferred to orthopaedics.

We present two cases with bilateral humeral head fracture, which were sequelae to a single unprovoked GTCSz and none of the patients were on any AEDs. Both of these patients were managed by closed reduction and internal pin fixation. Fractures occur in $1 \%$ of patients following a seizure, of which $0.3 \%$ are a result of the seizure alone. ${ }^{1}$ Typical position of the shoulder during a convulsion is adduction,
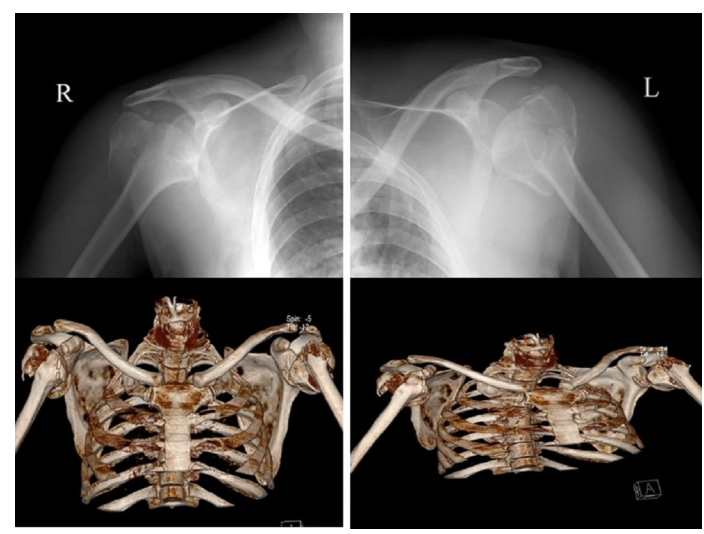

Figure 1 X-ray and CT of shoulders showing bilateral comminuted humeral head fracture and fracture fragment displacement.

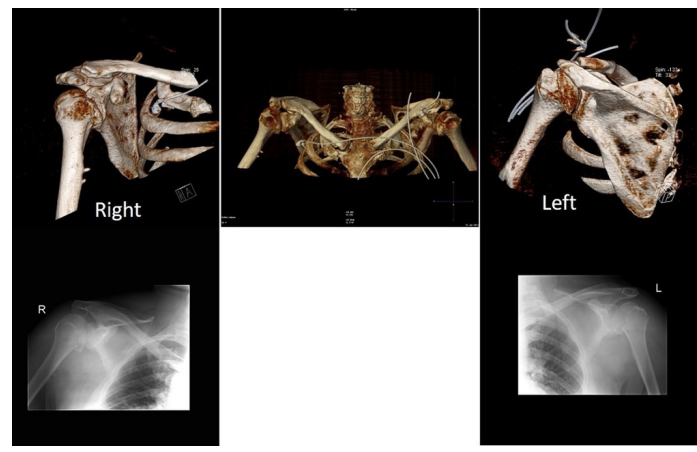

Figure 2 X-ray and CT of shoulders showing fracture in both humeral head.

internal rotation and flexion, with the spasm, the humeral head is forced superiorly and posteriorly over the glenoid cavity, resulting in fracture. It is possible that old age may be a contributory factor in this where muscles around the shoulder are laxed. A poor functional outcome after a proximal humeral fracture is not independently influenced by age in the elderly, and factors associated with social independence are more predictive of outcome. ${ }^{2}$ Humeral head fracture is often associated with poor long-term function regardless of the choice of treatment.

In contrast, patients who have a history of epilepsy on AEDs, there is a high risk of fracture dislocation, especially if they are elderly women. ${ }^{3}$ In addition, bone health, degree and severity of fall, laxed muscle with osteoporotic bones, all play a role in this complication.

We feel these two cases highlight the importance that the postseizure complication should lead to further evaluation and early assessment which can reduce pain and agony of these patients.

We feel our two unusual rare cases add to the literature that a devastating complication can occur as a part of a seizure and should be recognised and managed. Corrective surgery leads to early discharge of these patients.

\section{Learning points}

- Single generalised tonic clonic seizure can cause bilateral humeral head fracture without dislocation of shoulder.

- Shoulder pain postseizure should be investigated. 
Mostly, it is difficult to avoid these complications as the type and degree of fall postseizure along with severity of a GTCSz are not predictable. Although maintaining a healthy life style, physical activity and calcium supplementation can help bone health, especially in the fifth and sixth decade of life.

Acknowledgements We would like to thank Dr Heba ElHasin for her contribution and management of these patients.

Contributors We have submitted this article and have made following contributions as per the authors listed. AAA was responsible for patient's care acutely and has contributed for planning the manuscript based on different cases collected and recording of significant imaging findings, as sequence of events evolved and of acquisition of data. RR was responsible for patient's care acutely and has contributed for planning the manuscript based on different cases collected and recording of significant imaging findings, as sequence of events evolved, acquisition of data and follow-up. ARD was responsible for reporting of all the images, analysis of the data, interpretation of data and reviewing of the manuscript and providing images with legends. KAS was responsible for patient care immediate and acutely and has contributed for planning of this manuscript based in sequence of events, conception based on his varied experience as well as designing of the manuscript and acquisition of data.

Competing interests None declared.

Patient consent Obtained.

Provenance and peer review Not commissioned; externally peer reviewed.

(C) BMJ Publishing Group Ltd (unless otherwise stated in the text of the article) 2017. All rights reserved. No commercial use is permitted unless otherwise expressly granted.

\section{REFERENCES}

1 Finelli PF, Cardi JK. Seizure as a cause of fracture. Neurology 1989;39:858-60.

2 Clement ND, Duckworth AD, McQueen MM, et al. The outcome of proximal humeral fractures in the elderly: predictors of mortality and function. Bone Joint J 2014:96-B:970-7.

3 Souverein PC, Webb DJ, Weil JG, et al. Use of antiepileptic drugs and risk of fractures: case-control study among patients with epilepsy. Neurology 2006;66:1318-24.

Copyright 2017 BMJ Publishing Group. All rights reserved. For permission to reuse any of this content visit

http://group.bmj.com/group/rights-licensing/permissions.

BMJ Case Report Fellows may re-use this article for personal use and teaching without any further permission.

Become a Fellow of BMJ Case Reports today and you can:

- Submit as many cases as you like

- Enjoy fast sympathetic peer review and rapid publication of accepted articles

- Access all the published articles

Re-use any of the published material for personal use and teaching without further permission

For information on Institutional Fellowships contact consortiasales@bmjgroup.com

Visit casereports.bmj.com for more articles like this and to become a Fellow 